\title{
Os Termos de Referências como Fonte de Informações para a execução das atividades de Unidades de Alimentação e Nutrição Hospitalar
}

The Terms of Reference as a Source of Information for the accomplishment of the work of the Food Services in a hospital

Los Términos de Referencia como Fuente de Información para el desarrollo de las actividades de los Servicios de Alimentación en hospital

Luciana Alves Vieira Ferraz ORCID: https://orcid.org/0000-0002-1675-1082

Universidade Federal da Bahia, Brasil

E-mail: dumsalvador@ hotmail.com

Rita de Cássia Coelho de Almeida Akutsu ORCID: https://orcid.org/0000-0003-0699-7617 Universidade de Brasília, Brasil E-mail: rita.akutsu@gmail.com Jamacy Costa-Souza ORCID: https://orcid.org/0000-0003-4198-351X Universidade Federal da Bahia, Brasil E-mail: jamacy@ufba.br

Maria da Purificação Nazaré Araújo ORCID: https://orcid.org/0000-0002-8279-4769 Universidade Federal da Bahia, Brasil E-mail: puri@ufba.br

\begin{abstract}
Resumo
Objetivou-se avaliar as informações disponíveis nos Termos de Referências acerca das atividades das Unidades de Alimentação e Nutrição hospitalares. Estudo exploratório, a partir dos TR de oito hospitais estaduais da Bahia que terceirizam as suas UAN. Foi elaborado instrumento com 32 afirmações divididas em três fatores: Planejamento de Cardápios, Execução de Cardápios e Controle higiênico-sanitário, avaliadas, também, se eram explícitas ou não. O fator Planejamento de Cardápios apresentou 57,5\% de itens presentes nos Termos de Referência, enquanto Execução de Cardápios e Controle higiênico-sanitário obtiveram, respectivamente, $66,7 \%$ e 80,7\%. Apenas o primeiro fator não teve o mesmo percentual em relação aos itens que foram declarados explicitamente. Verificou-se a falta de informações essenciais para a execução das atividades de uma Unidade de Alimentação e Nutrição hospitalar, como: o responsável por elaborar os cardápios, dimensionamento de pessoal, higienização do reservatório de água e capacitação dos manipuladores. Conclui-se pela necessidade de TR mais específicos.
\end{abstract}

Palavras-chave: Serviços terceirizados; Contratos; Termo de referência; Unidade de alimentação e nutrição.

\begin{abstract}
The aim of this study was to review the information provided by the Terms of Reference related to the activities of the Food and Nutrition Units in hospitals. This was an exploratory study, based on the TRs of eight state-run hospitals in Bahia that outsource their Food Services. An instrument was drafted with 32 assertions organized into three categories: Menu Planning, Menu Execution, and Hygiene and Sanitary Control. Whether or not they were explicit was also considered. Menu Planning had 57.5\% of items included in the Terms of Reference, while Menu Execution and Hygiene and Sanitary Control reached $66.7 \%$ and $80.7 \%$, respectively. Only the first item did not have the same percentage in relation to the topics that were explicitly stated. The lack of essential information for the execution of the activities of a Food Services in a hospital was verified, including: the person responsible for elaborating the menus, staff sizes, hygienization of the water tanks, and training of workers. The conclusion is that more specific TRs are needed.
\end{abstract}

Keywords: Outsourced services; Contracts; Term of reference; Food services. 


\begin{abstract}
Resumen
El objetivo fue evaluar la información disponible en los Términos de Referencia sobre las actividades de los Servicios de Alimentación. Estudio exploratorio basado en el RT de ocho hospitales estatales de Bahía que subcontratan su Servicio. Se elaboró un instrumento con 32 enunciados divididos en tres factores: Menús de Planificación, Ejecución de Menús y Control Higiénico-Sanitario, los cuales también fueron evaluados si eran explícitos o no. El factor Planificación de Menú tuvo 57,5\% de los ítems presentes en los Términos de Referencia, mientras que Ejecución de Menú y Control Higiénico-Sanitario obtuvieron, respectivamente, 66,7\% y 80,7\%. Solo el primer factor no tuvo el mismo porcentaje en relación a los ítems que fueron declarados explícitamente. Faltaba información imprescindible para la realización de las actividades de un Servicio de Alimentácion en hospital, como: el responsable de la elaboración de los menús, el dimensionamiento del personal, la limpieza del depósito de agua y la formación de los manipuladores. Se concluye por la necesidad de un RT más específico.
\end{abstract}

Palabras clave: Servicios externos; Contratos; Término de referencia; Servicios de alimentación.

\title{
1. Introdução
}

As Unidades de Alimentação e Nutrição (UAN) têm sido definidas como espaços destinados à produção e ou ao fornecimento de refeições para coletividade. Representa uma unidade administrativa organizada, abrangendo desde o planejamento da aquisição de alimentos e seleção de fornecedores até a análise dos efeitos da alimentação servida. A qualidade dos serviços prestados depende diretamente de aspectos de segurança microbiológica e físico-química dos alimentos e, também, do seu valor dietético e nutricional (Mello, Schineider, Lima, Frazon \& Costa, 2013; Abreu, Spinelli \& Pinto, 2011; Teixeira, Oliveira, Rego \& Biscontini, 1990).

Considerada uma atividade meio, em razão do efeito da alimentação na terapêutica em hospitais geridos pela Administração Pública, geralmente a UAN é uma das principais áreas em que ocorre a terceirização (Souza, Lara, Lima \& Xavier, 2011).

A terceirização é um modelo de gestão em que a Administração Pública contrata os serviços de particulares, não devendo ser confundida com contração de mão-de-obra (Vieira, 2013). No Brasil, ela tornou-se possível a partir de 1967, quando da publicação do Decreto-Lei n. 200 (1967), que dispôs sobre a organização da Administração Federal.

A Lei das Licitações e Contratos, a Lei n. 8666 (1993), regulamenta o inciso XXI do art. 37 da Constituição Federal da República Federativa do Brasil (1988), determinando que a contratação de terceiros deve ser precedida de licitação. As licitações são divididas em seis modalidades (concurso, concorrência, tomada de preço, convite, leilão e pregão) (Lei n. 10.520, 2002; Lei n. 8.080, 1990) e duas fases (interna, antes do edital; externa, depois do edital).

Na fase Interna, são elaborados os Termos de Referências (TR), instrumentos utilizados para a contratação de serviços na modalidade pregão da licitação, equivalentes ao Projeto Básico da Lei de Licitações e Contratos (Vieira, 2013; Lei n. $10.520,2002)$.

De acordo com o Decreto n. 10.024 (2019), que regulamenta o pregão na forma eletrônica, os TR devem conter informações como: deveres do contratado e contratante; prazo de execução e sanções; estratégia para fiscalização e gerenciamento; entre outros. O TR para prestação de serviços na área de alimentação coletiva tem as suas especificidades, exigindo uma atenção especial (Colares, Figueiredo, Martins \& Andrade, 2014) para permitir que as atividades das UAN ocorram de forma a garantir a qualidade higiênico-sanitária das refeições servidas, evitando, por exemplo, as Doenças Veiculadas por Alimentos (DVA) (Silva Júnior, 2013). A fase externa compreende as etapas com o objetivo de selecionar a melhor proposta para celebração do contrato desejado pela Administração Pública (Colares et al., 2014).

Segundo a Associação Brasileira das Empresas de Refeições Coletivas (ABERC), as prestadoras de serviços são responsáveis por fornecer 14,7 milhões de refeições/dia no ano de 2020. O Setor é responsável ainda por empregar cerca de 250 mil trabalhadores, tendo em 2020 faturamento próximo a R \$ 23 bilhões (Associação Brasileira de Empresas de Refeições, Coletivas,[ABERC],2021). 
A importância econômica do Setor de Refeições Coletivas e a escassez de estudos na área de nutrição que aprofundem o conhecimento nos contratos de terceirização motivaram o desenvolvimento desta investigação. Neste sentido, o objetivo deste estudo foi avaliar as informações disponíveis nos Termos de Referências sobre as atividades das UAN hospitalares.

\section{Metodologia}

Trata-se de um estudo qualitativo realizado a partir de análise documental, do tipo exploratório, sobre os Termos de Referências dos contratos firmados pelos hospitais públicos da Bahia e a Secretaria de Saúde do Estado da Bahia (SESAB) com as empresas concessionárias de alimentação.

\subsection{Fonte de dados}

Os Termos de Referências e os Contratos foram disponibilizados pela SESAB, totalizando oito TR que abrangem hospitais estaduais da capital e do interior. Esses documentos aparecem como Anexo dos contratos, assim como as obrigações da contratante e da contratada mais específicas ao serviço, que foram imprescindíveis para avaliar os itens propostos.

Atualmente, a rede hospitalar da SESAB é composta por 54 unidades de saúde, envolvendo Hospitais, Maternidades, Unidades de Pronto Atendimento 24h e de Emergência, e Centros de Referência. São 35 hospitais estaduais, 13 na capital e 22 no interior; e 6 maternidades. Em relação ao modelo de gestão, 17 estão sob gestão direta da SESAB, 18 sob gestão indireta e 2 sob gestão por Parceria Público-Privada (PPP).

Foram oito contratos e Termos de Referência disponibilizados pela Secretaria de Saúde de sete contratadas diferentes, assinados entre 2013 e 2016, com vigência máxima de cinco anos, de acordo com o preconizado pelo artigo 57 da Lei n. 8666 (1993). Destes, cinco são de hospitais do município de Salvador e os outros três são dos municípios de Lauro de Freitas, Feira de Santana e Ilhéus. Os hospitais variam bastante quanto a capacidade (de, aproximadamente, 80 a 700 leitos) e as especialidades (geral, psiquiátrico e doenças respiratórias).

Todos os hospitais eram responsáveis pelo fornecimento de refeições aos pacientes, funcionários e acompanhantes em apenas um deles não se fornecia alimentação aos acompanhantes, por ser um centro de internação.

\subsection{Construção dos itens}

Os TR foram avaliados tendo como referência a Resolução da Diretoria Colegiada n. 216 (2004), regulamento Técnico de Boas Práticas para Serviços de Alimentação, a partir de afirmações que avaliaram as informações para o bom funcionamento da UAN hospitalar.

A construção das Tabelas seguiu o descrito na Figura 1. 
Figura 1. Estágios da elaboração das afirmações para avaliação dos Termos de Referência dos contratos.
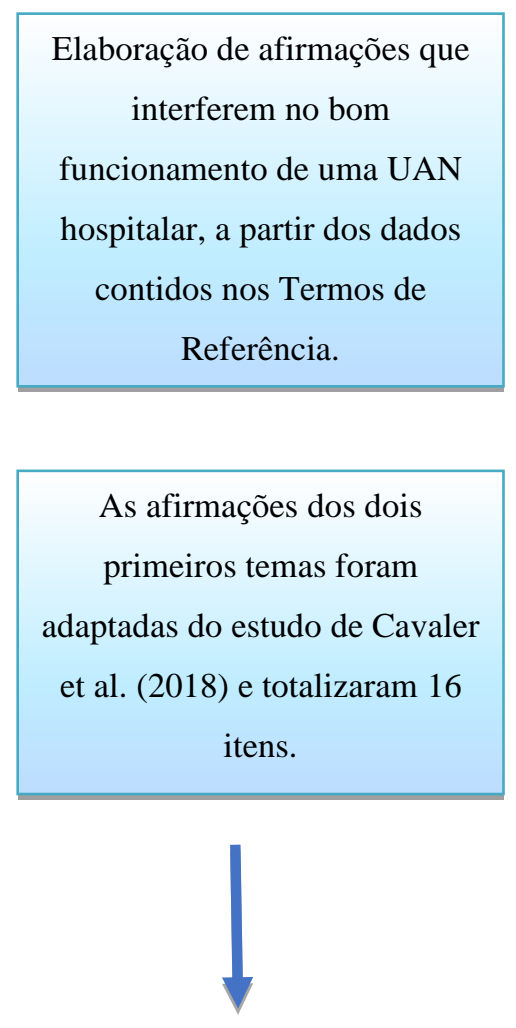

As afirmações do tema restante foram elaboradas a partir da RDC n. 216 (2004), totalizando 16 itens.

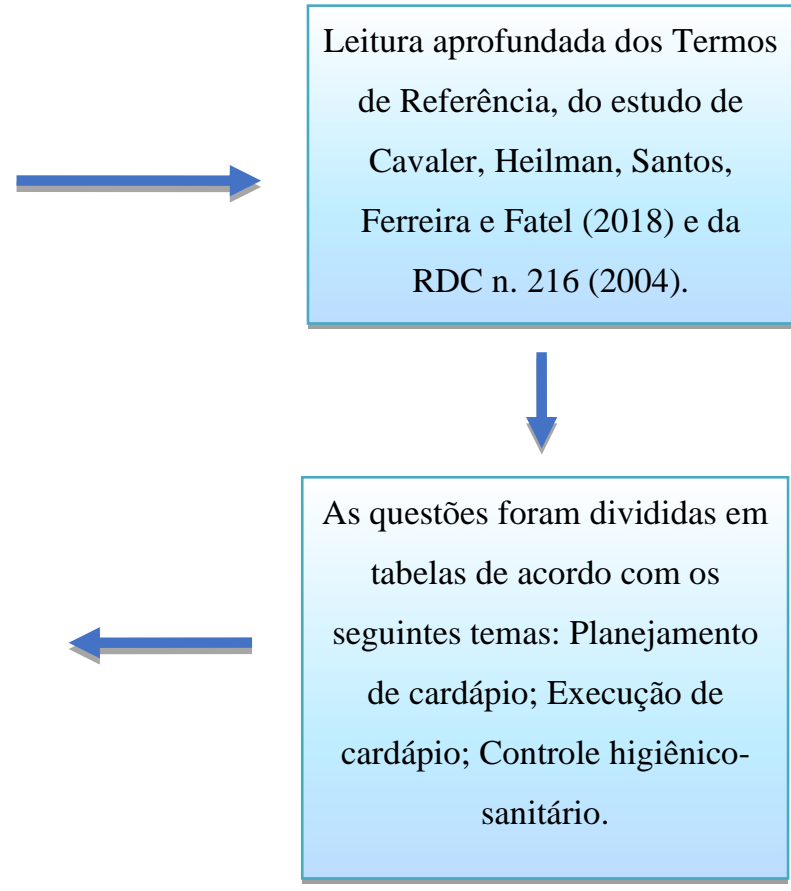

As 32 afirmações foram verificadas de acordo com sua presença ou não e, caso a resposta fosse positiva, foi avaliado se a informação foi declarada de forma explícita.

Fonte: Autores.

As afirmações dizem respeito às diversas atividades que são inerentes ao funcionamento de uma UAN. A saber:

- Planejamento de cardápio: informações acerca das porções ou quantidades per capita e frequência das preparações; uso de ficha técnica de preparação; responsável pela elaboração dos cardápios; qualidade dos produtos adquiridos; tipos e cortes de carnes; hábito e cultura alimentar; cardápios específicos para portadores de necessidades especiais (alimentação).

- Execução de cardápios: presença de nutricionista; etapas do pré-preparo e preparo; controle de sobras; reaproveitamento de alimentos; satisfação dos usuários.

- Controle higiênico-sanitário: controle de temperaturas durante o processo produtivo; controle de pragas e vetores; lavagem do tanque; higienização do ambiente, dos equipamentos e utensílios e dos alimentos; coleta de amostras; referência a legislação sanitária; presença do Manual de Boas Práticas. Este fator também abrangeu perguntas sobre os manipuladores: em relação à vestimenta, ao controle de saúde e à capacitação. 
A presença da informação nos Termos de Referências e se ela estava declarada explicitamente foi julgada pela pesquisadora com experiência em administração de serviços na área de alimentação coletiva. Foi considerado se a informação da forma que estava contida no TR contribuía efetivamente para auxiliar no bom funcionamento da UAN.

Cada tema abordado nesta pesquisa foi nomeado como fator e cada afirmação também foi nomeada como item.

\subsection{Análise dos dados}

Os TR foram analisados de acordo com a análise de conteúdo proposta por Bardin (2016). Esta análise é dividida em três etapas: pré-análise, exploração do material e tratamento dos resultados. A primeira fase, também chamada de organização, possui três atividades principais: a escolha dos documentos - que neste estudo são os termos de referências; a formulação das hipóteses e dos objetivos; e a elaboração de indicadores para fundamentar a interpretação final. Estas atividades devem ser precedidas pela leitura flutuante, ou seja, o conhecimento dos documentos que serão analisados. Na etapa seguinte, a mais trabalhosa, os documentos são codificados por procedimentos que devem relacionar-se com os objetivos da pesquisa. Por fim, os dados brutos são tratados e interpretados, tornando-os em dados significativos e válidos.

Utilizou-se, também, a estatística descritiva, a partir de frequências e percentuais para cada afirmativa, com o propósito de julgá-las quanto ao estarem declaradas explicitamente ou não, e também para avaliar o total de respostas de cada fator.

Para o cálculo das frequências e percentuais, considerou-se que cada item poderia atingir o total de oito pontos, em que cada ponto corresponde a um hospital avaliado. Para obter os percentuais, foram somados os totais de pontuações obtidas em cada item, dividindo pelo total de pontos possíveis em cada bloco, de acordo com o número total de itens. O mesmo foi realizado para verificar a porcentagem dos itens que foram declarados explicitamente.

Para os resultados encontrados em cada fator foram confeccionadas Tabelas, sendo que uma delas é uma síntese dos dados encontrados. Apenas percentuais acima de 70\% foram considerados satisfatórios.

Este estudo foi aprovado pelo Comitê de Ética em Pesquisa com Seres Humanos da Escola de Nutrição da Universidade Federal da Bahia conforme parecer número: 2.735.277/2018. Foi parcialmente financiado pela Fundação de Amparo à Pesquisa do Estado da Bahia, edital PPSUS 2013, Termo de Outorga SUS0025/2013 e, também, por bolsas de iniciação científica.

\section{Resultados e Discussão}

Os Termos de Referências foram analisados de acordo com as afirmações apresentadas nas tabelas a seguir.

Os resultados acerca do Planejamento de Cardápios (Tabela 1) atingiram o menor percentual, correspondendo a $54,9 \%$ de itens presentes. Os itens cárneos foram escolhidos na avaliação pelo maior custo no planejamento de cardápios. Dos dez itens avaliados, três estavam ausentes em todos os TR: frequência das preparações; elaboração dos cardápios por nutricionistas; exigência para considerar os hábitos e cultura alimentar. Foi possível observar ainda que, apesar de presente nos TR, as informações sobre qualidade dos produtos a serem adquiridos e sobre preparações com restrições alimentares não estavam explícitas nos contratos, o que fez com que a avaliação dos itens atingisse apenas $27,5 \%$. 
Tabela 1. Informações dos Termos de Referências dos contratos de terceirização para Planejamento de Cardápios em UAN hospitalares estaduais. Salvador-BA, 2019.

Planejamento de cardápios

\begin{tabular}{|c|c|c|c|c|}
\hline \multirow{2}{*}{ Afirmações } & \multicolumn{2}{|c|}{ Sim } & \multicolumn{2}{|c|}{$\begin{array}{l}\text { Declarado } \\
\text { explicitamente }\end{array}$} \\
\hline & $\mathrm{N}$ & $\%$ & $\mathrm{n}$ & $\%$ \\
\hline $\begin{array}{l}\text { Os contratos apresentam as porções ou quantidades per capitas } \\
\text { das preparações. }\end{array}$ & 8 & 100 & 0 & 0 \\
\hline Os contratos apresentam as frequências das preparações. & 0 & 0 & - & - \\
\hline $\begin{array}{l}\text { Há a obrigatoriedade da utilização da ficha técnica de } \\
\text { preparação. }\end{array}$ & 1 & 12,5 & 1 & 12,5 \\
\hline A elaboração dos cardápios por nutricionista é obrigatória. & 0 & 0 & - & - \\
\hline $\begin{array}{l}\text { Informação sobre a qualidade dos produtos a serem adquiridos } \\
\text { é encontrada. }\end{array}$ & 8 & 100 & 0 & 0 \\
\hline Definição dos tipos de carnes para cada preparação. & 8 & 100 & 8 & 100 \\
\hline Definição dos tipos de cortes para cada tipo de preparação. & 8 & 100 & 8 & 100 \\
\hline $\begin{array}{l}\text { Programação para a entrada de mercadorias de acordo com a } \\
\text { capacidade do estoque. }\end{array}$ & 5 & 62,5 & 5 & 62,5 \\
\hline $\begin{array}{l}\text { São exigidos que hábitos e culturas alimentares sejam } \\
\text { contemplados. }\end{array}$ & 0 & 0 & - & - \\
\hline $\begin{array}{l}\text { Presença de informações sobre preparações para paciente com } \\
\text { necessidades especiais (alergias, intolerâncias, patologias). }\end{array}$ & 7 & 87,5 & 0 & 0 \\
\hline TOTAL & 45 & 54,9 & 22 & 27,5 \\
\hline
\end{tabular}

Fonte: Autores.

No fator Execução de Cardápio (Tabela 2), do total de itens avaliados (seis), apenas dois não obtiveram pontuação máxima: controle de sobras e avaliação da satisfação dos usuários. O mesmo ocorreu para os itens declarados explicitamente. 
Tabela 2. Informações dos Termos de Referências dos contratos de terceirização para a execução de cardápios em UAN hospitalares estaduais. Salvador-BA, 2019.

\section{EXECUÇÃO DE CARDÁPIOS}

\begin{tabular}{|c|c|c|c|c|}
\hline \multirow[t]{2}{*}{ Afirmações } & \multicolumn{2}{|c|}{ Sim } & \multicolumn{2}{|c|}{$\begin{array}{l}\text { Declarado } \\
\text { explicitamente }\end{array}$} \\
\hline & $\mathrm{N}$ & $\%$ & $\mathrm{n}$ & $\%$ \\
\hline $\begin{array}{l}\text { Exigência da presença de nutricionista para o acompanhamento } \\
\text { das atividades. }\end{array}$ & 8 & 100 & 8 & 100 \\
\hline $\begin{array}{l}\text { Informações sobre a forma como deve ser realizado o pré-preparo } \\
\text { e preparo das refeições e as demais etapas de produção. }\end{array}$ & 8 & 100 & 8 & 100 \\
\hline $\begin{array}{l}\text { Exigência de controle de temperatura nas etapas do processo } \\
\text { produtivo. }\end{array}$ & 8 & 100 & 8 & 100 \\
\hline Obrigatoriedade do controle de sobras. & 0 & 0 & - & - \\
\hline Informações sobre o reaproveitamento das refeições. & 8 & 100 & 8 & 100 \\
\hline A satisfação dos usuários deve ser avaliada. & 0 & 0 & - & - \\
\hline TOTAL & 32 & 66,7 & 32 & 66,7 \\
\hline
\end{tabular}

Fonte: Autores.

O fator com maior número de itens, 16 no total, Controle Higiênico-sanitário (Tabela 3) foi o que obteve, também, a maior pontuação entre os fatores: 104 pontos dos 128 possíveis, totalizando 80,7\%. Em nenhum dos termos foram encontradas informações sobre a exigência da lavagem do reservatório de água e, consequentemente, a frequência da realização dessa atividade. Informações sobre controle de pragas e Manual de Boas Práticas não estavam presentes em apenas um TR. A capacitação dos funcionários foi o único item que só constava em três. 
Tabela 3. Informações dos Termos de Referências dos contratos de terceirização sobre questões relacionadas ao controle higiênico-sanitário das UAN. Salvador-BA, 2019.

\section{CONTROLE HIGIENICO-SANITÁRIO}

\begin{tabular}{|c|c|c|c|c|}
\hline \multirow[t]{2}{*}{ Afirmações } & \multicolumn{2}{|c|}{ Sim } & \multicolumn{2}{|c|}{ Declarado explicitamente } \\
\hline & $\mathrm{N}$ & $\%$ & $\mathrm{~N}$ & $\%$ \\
\hline O controle de pragas é exigido. & 7 & 87,5 & 7 & 87,5 \\
\hline A frequência de controle de pragas é estipulada. & 7 & 87,5 & 7 & 87,5 \\
\hline A lavagem do tanque é obrigatória. & 0 & 0 & - & - \\
\hline A frequência da lavagem dos tanques é estipulada. & 0 & 0 & - & - \\
\hline A higienização do ambiente é descrita. & 8 & 100 & 8 & 100 \\
\hline $\begin{array}{l}\text { Orientação como e com que frequência deve ser realizada a } \\
\text { higienização do ambiente. }\end{array}$ & 8 & 100 & 8 & 100 \\
\hline A higienização dos equipamentos e utensílios é descrita. & 8 & 100 & 8 & 100 \\
\hline $\begin{array}{l}\text { Orientação de como e com que frequência deve ser realizada a } \\
\text { higienização dos equipamentos e utensílios. }\end{array}$ & 8 & 100 & 8 & 100 \\
\hline A higienização dos alimentos é descrita. & 8 & 100 & 8 & 100 \\
\hline $\begin{array}{l}\text { Orientação sobre como e com que frequência deve ser realizada a } \\
\text { higienização dos alimentos. }\end{array}$ & 8 & 100 & 8 & 100 \\
\hline Os contratos citam a legislação sanitária. & 8 & 100 & 8 & 100 \\
\hline $\begin{array}{l}\text { O Manual de Boas Práticas e/ou os Procedimentos Operacionais } \\
\text { Padrão é exigido. }\end{array}$ & 7 & 87,5 & 7 & 87,5 \\
\hline A coleta e análise de amostras dos alimentos fornecidos é exigida. & 8 & 100 & 8 & 100 \\
\hline A vestimenta dos manipuladores é descrita. & 8 & 100 & 8 & 100 \\
\hline
\end{tabular}

CONTROLE HIGIENICO-SANITÁRIO

\begin{tabular}{|c|c|c|c|c|}
\hline \multirow{2}{*}{ Afirmações } & \multicolumn{2}{|c|}{ Sim } & \multicolumn{2}{|c|}{ Declarado explicitamente } \\
\hline & $\mathrm{N}$ & $\%$ & $\mathrm{~N}$ & $\%$ \\
\hline O controle de saúde dos manipuladores é item obrigatório. & 8 & 100 & 8 & 100 \\
\hline A capacitação dos manipuladores é imposta. & 3 & 37,5 & 3 & 37,5 \\
\hline TOTAL & 104 & 81,5 & 104 & 81,5 \\
\hline
\end{tabular}

Fonte: Autores.

O total dos percentuais de sim e dos itens declarados explicitamente obtidos em cada fator está descrito na Tabela 4. Reitera-se positivamente a presença dos itens nos TR sobre Controle Higiênico-sanitário e, negativamente, os itens sobre Planejamento de Cardápios.

Ao avaliar todos os itens em conjunto, o percentual de sim foi de 70,7\% e de itens declarados explicitamente foi de $61,7 \%$ (Tabela 4$)$. 
Tabela 4. Total da pontuação dos fatores avaliados e total do instrumento, de acordo com as informações contidas nos Termos de Referência. Salvador, 2019.

\begin{tabular}{|c|c|c|c|c|}
\hline \multirow[t]{2}{*}{ Fator } & \multicolumn{2}{|c|}{$\begin{array}{l}\text { Pontuação } \\
\text { SIM }\end{array}$} & \multicolumn{2}{|c|}{$\begin{array}{c}\text { Pontuação } \\
\text { Declarados explicitamente }\end{array}$} \\
\hline & $\mathrm{N}$ & $\%$ & $\mathrm{~N}$ & $\%$ \\
\hline Planejamento de Cardápio & 45 & 54,9 & 22 & 27,5 \\
\hline Execução de Cardápio & 32 & 66,7 & 32 & 66,7 \\
\hline Controle Higiênico-Sanitário & 104 & 81,5 & 104 & 81,5 \\
\hline TOTAL & 181 & 70,7 & 158 & 61,7 \\
\hline
\end{tabular}

Fonte: Autores.

\section{Discussão}

A produção de refeições em UAN deve ter como objetivo o fornecimento de uma alimentação adequada às recomendações nutricionais para os comensais. Devem ser balanceadas de acordo com os padrões dietéticos e higiênicos, ajustados aos limites estruturais e financeiros da instituição (Abreu et al., 2013).

\subsection{Fator 1: planejamento de cardápios}

Os TR trazem as gramaturas específicas para cada preparação, porém destaca-se que essas gramaturas dizem respeito à quantidade per capita da preparação pronta para consumo. No entanto, sabe-se que per capita é a quantidade de alimento cru destinado a uma pessoa (Araújo, Botelho, Akutsu \& Araújo, 2016), o que mostra que a informação é equivocada e pode gerar impasses na aquisição de produtos e, consequentemente no custo, principalmente pelo per capita ser um indicador de previsibilidade.

Apesar de não existirem informações sobre as frequências das preparações, há ressalvas pontuais sobre a programação de algumas delas. Exemplos: para os pratos principais do almoço e do jantar, em sete contratos era exigida a programação de uma opção. Para as sobremesas do almoço e do jantar, cinco contratos trazem sobre a frequência, sendo que quatro deles exigem duas opções de sobremesa e uma delas tendo que ser, obrigatoriamente, uma fruta. Ao avaliar os editais de licitação de restaurantes universitários das universidades federais do Sul do Brasil, Cavaler et al. (2018) constataram uma realidade diferente: a maior parte dos trinta e cinco editais analisados continha informações sobre as quantidades per capitas e frequências das preparações. A frequência mensal dos alimentos e/ou preparações para a composição do cardápio é imprescindível para nortear a execução da prestação de serviço (Colares et al., 2014).

Dada a limitação de não termos acessado o cardápio dos hospitais, não se pôde avaliar os impactos na variedade das preparações, por conta da falta de informações sobre a frequência dos alimentos servidos.

As fichas técnicas são ferramentas úteis para o planejamento de cardápios por conterem dados sobre: quantidade per capita, fator de correção e cocção, composição centesimal em macro e micronutrientes da preparação, o rendimento e o número de porções, ingredientes e equipamentos utilizados, custo da preparação, entre outros (Akutsu, Botelho, Camargo, Sávio \& Araújo, 2018). As fichas técnicas só foram exigidas em um TR, o que ocasiona a falta de padronização das preparações, dificultando o controle de custos e do cálculo nutricional da refeição.

Nenhum dos TR exige que os cardápios sejam confeccionados sob supervisão do nutricionista. Isso pode ser pelo fato da Lei n. 8234 (1991), que regulamenta a profissão do nutricionista, já trazer essa obrigatoriedade. O cardápio é definido como 
"conjunto de alimentos e preparações destinadas ao consumo humano, planejados em conformidade com as necessidades nutricionais e fisiológicas do indivíduo ou coletividade" e é a parte crucial no planejamento das atividades (Conselho Federal de Nutricionistas [CFN], 2018). Conhecimentos inerentes à formação do nutricionista quanto, aos métodos de cocção, cores dos alimentos, grupos alimentares a serem ofertados diariamente, por exemplo, podem influenciar negativamente na recuperação/manutenção do estado nutricional do indivíduo.

Todos os TR têm um item "elaboração de cardápio" e nele contém a seguinte informação: "os cardápios deverão apresentar preparações variadas, equilibradas e de boa aparência, proporcionando um aporte calórico necessário e uma boa aceitação". Informações quanto aos meios de atingir esses objetivos não estão descritas. De acordo com os contratos, essas normas deverão ser estabelecidas posteriormente pelo Serviço de Nutrição do contratante.

Sobre a qualidade dos produtos, todos os termos de referências trazem com frequência a expressão "produto de $1^{\mathrm{a}}$ qualidade" ou "produto de boa qualidade" para os gêneros alimentícios (perecíveis, semi-perecíveis, não-perecíveis e fórmulas enterais), produtos descartáveis (embalagens, talheres, copos, guardanapos) e produtos de higienização. Um exemplo: nos termos há a seguinte informação: "todos os gêneros alimentícios empregados na elaboração das refeições deverão ser, obrigatoriamente, de primeira qualidade e estar em perfeitas condições de conservação, higiene e apresentação". Itens como ovo, arroz, leite, verduras, frutas e legumes possuem especificações mais claras, tais como: "as verduras, frutas e legumes deverão ser frescos, sem manchas, sem rachaduras, sem áreas machucadas, com pedúnculos preservados e de primeira qualidade".

No entanto, o termo "qualidade" ou de "boa qualidade" trata-se de uma expressão vaga, sem consequência objetiva. Para se ter mais clareza, deveria existir para cada produto um Padrão de Identidade e Qualidade (PIQ), definindo o conjunto de características que identificam e qualificam o produto para orientar na aquisição de matérias-primas (Agência Nacional de Vigilância Sanitária [ANVISA], 1993). Caberia ao contratante, ainda, fiscalizar periodicamente os PIQ (Colares et al., 2014).

Diferentemente dos outros itens, para os tipos e cortes de carnes há um detalhamento expressivo nos termos. Uma explicação possível é o impacto desse no custo das refeições, uma vez que representam, em média, de 39\% a 58\% dos custos dos componentes do cardápio (Abreu et al., 2013).

Estoque corresponde ao total de mercadorias (mercadorias, insumos, matérias-primas, materiais ou suprimentos) de uma empresa para a venda ou consumo próprio. Tem como objetivos a facilidade em ter os itens disponíveis, a prevenção contra erros de planejamento e/ou erros de previsão ou registros imprecisos, a redução do custo devido as compras em quantidades ótimas, bem como atender variações de demanda, variações climáticas, atraso de fornecedores, dentre outros (Abreu et al., 2013). A maioria dos TR (62,5\%) traz uma preocupação com o controle da entrada de mercadorias: "programar entrada de mercadorias de maneira que não sobrecarregue o estoque, conforme orientação da contratante", visto que estoques acima da capacidade prevista podem dificultar o controle de saída das mercadorias, além de interferir na qualidade dos produtos.

Os TR não trouxeram informações sobre a elaboração dos cardápios levando em consideração os hábitos e cultura dos comensais, ameaçando a Segurança Alimentar e Nutricional (SAN). Cavaler et al. (2018) encontrou essas informações em $45,71 \%$ dos editais.

Segundo a Lei n. 11.346 (2006), no seu artigo $3^{\circ}$, a SAN é caracterizada como o direito de todos ao acesso regular e permanente a alimentos de qualidade, em quantidade suficiente, sem comprometer o acesso a outras necessidades essenciais, tendo como bases práticas alimentares promotoras de saúde que respeitem a diversidade cultural e que sejam ambiental, cultural, econômica e socialmente sustentáveis.

Os TR trazem informações sobre as dietas restritas, porém não de forma explícita, o que pode não atender às especificidades de pacientes com essas dietas. 


\subsection{Fator 2: execução de cardápios}

Nos TR foi constatada a obrigatoriedade do nutricionista na fiscalização das atividades durante o processo produtivo, assim como determina a Lei n. 8234 (1991).

Apesar de apontar a necessidade desse profissional e de afirmar que o técnico em nutrição não o substitui, as categorias dos demais profissionais que devem fazer parte do quadro só são listadas em um dos termos. Outro contém a informação que os auxiliares de cozinha não substituem o cozinheiro. O dimensionamento dos colaboradores também é tratado de forma superficial. Em três termos são citadas as referências para copeiras (30 pacientes para cada) e nutricionista (é citada a Resolução n. 360/2005 - atualmente substituída pela Resolução n. 600/2018), mas nenhum outro dado foi verificado (Conselho Federal de Nutricionistas [CFN], 2018; Conselho Federal de Nutricionistas [CFN], 2005; Lei n. 8.234, 1991). A gestão de pessoas (dimensionamento dos cargos, qualificação, recrutamento, seleção, treinamento e motivação pessoal) nas UAN deve ser bem administrada para evitar a rotatividade da mão-de-obra e permitir a melhoria dos serviços (Abreu et al., 2012).

As etapas do processo produtivo são minuciosamente detalhadas, diferente do encontrado por Cavaler et al. (2018). Há informações quanto ao recebimento dos produtos de origem animal, dos hortifrutigranjeiros, de leite e derivados, dos estocáveis, dos materiais de limpeza, dos descartáveis, dos sucos, polpas e dos produtos industrializados com as suas respectivas temperaturas de recebimento, com exceção dos materiais de limpeza. Ainda há orientações para verificação das condições dos veículos dos fornecedores, da higiene pessoal e da adequação do uniforme do entregador, da correta rotulagem dos alimentos, da avaliação sensorial, das condições da embalagem, entre outros itens dos produtos.

$\mathrm{Na}$ seção sobre armazenamento existiam orientações quanto a correta disposição dos produtos, sobre seguir o sistema PVPS (primeiro que vence, primeiro que sai), sobre a separação dos produtos para devolução dos demais, sobre o uso de etiquetas nos produtos após abertos e a exigência do registro das temperaturas dos equipamentos. Sobre o pré-preparo e preparo são indicados cuidados com as temperaturas de segurança, assim como evitar contaminação cruzada, proteger os alimentos depois de prontos e registrar as temperaturas em planilhas próprias.

Os cuidados nas etapas do processo produtivo devem garantir as Boas Práticas definidas na RDC n. 216 (2004) como "procedimentos que devem ser adotados por serviços de alimentação a fim de garantir a qualidade higiênico-sanitária e a conformidade dos alimentos com a legislação sanitária".

Dois pontos também importantes durante as etapas do processo produtivo são o controle de sobras e o reaproveitamento das refeições, pois avaliam a qualidade do serviço (desperdício). Os termos de referência trazem o seguinte quanto as sobras: "desprezar após cada refeição a sobra de alimentos" e quanto ao reaproveitamento: "preparar as refeições no mesmo dia para consumo por pessoal especializado".

A qualidade do serviço também pode ser avaliada a partir da satisfação dos usuários para se obter uma percepção realista e atualizada (Ramos, Souza, Fernandes \& Xavier, 2013). Com os resultados é possível a adequação dos produtos e serviços que não agradaram os comensais e melhorar a relação com eles. A satisfação dos usuários é expressada nos TR como forma de fornecer refeições com uma boa aceitação, porém não é orientado como deve ser mensurada.

\subsection{Fator 3: controle higiênico-sanitário}

No terceiro bloco, sobre o controle higiênico-sanitário, a lavagem do reservatório de água, item não mencionado nos TR, é de grande importância por garantir, juntamente com a análise da potabilidade, a qualidade da água a ser consumida e utilizada nas preparações (RDC n. 216, 2004).

No item obrigações do principal no TR encontra-se a seguinte informação: "Manter parceria contínua com a CONTRATADA considerando as cláusulas do Edital, com finalidade de garantir um Serviço Técnico de Qualidade obedecendo CONTRATADA e CONTRATANTE as normas relativas à Regulação de Alimentos, Vigilância Sanitária e 
Saúde". Quanto às legislações sanitárias, a mais citada é a Portaria CVS n. 6 (1999) (estabelece os Parâmetros e Critérios para o Controle Higiênico-Sanitário em Estabelecimentos de Alimento), portaria esta do estado de São Paulo e, portanto, sem aplicabilidade no estado da Bahia. Apenas um contrato traz de forma clara a RDC n. 216 (2004), de abrangência nacional como a legislação que deve ser seguida durante a execução das atividades.

Todas as questões de Boas Práticas devem estar presentes no Manual de Boas Práticas, definido pela RDC n. 216 (2004), como:

"O documento que descreve as operações realizadas pelo estabelecimento, incluindo, no mínimo, os requisitos higiênico-sanitários dos edifícios, a manutenção e higienização das instalações, dos equipamentos e dos utensílios, o controle da água de abastecimento, o controle integrado de vetores e pragas urbanas, a capacitação profissional, o controle da higiene e saúde dos manipuladores, o manejo de resíduos e o controle e garantia de qualidade do alimento preparado."

Este documento deve estar disponível para os funcionários e para a autoridade sanitária. Estudo realizado por Seta, O’Dwyer, Henriques e Sales (2010) verificou que de oito hospitais públicos, em quatro estados brasileiros, nenhum deles apresentou o Manual atualizado, documentado e devidamente implantado.

Outro documento importante é o Procedimento Operacional Padrão (POP), definido como: "procedimento escrito de forma objetiva que estabelece instruções sequenciais para a realização de operações rotineiras e específicas na manipulação de alimentos". Devem ser implementados POP sobre: higienização de instalações, equipamentos e móveis; controle integrado de vetores e pragas urbanas; higienização do reservatório; higiene e saúde dos manipuladores (RDC n. 216 2004). Apenas dois contratos trouxeram a informação de obrigatoriedade do Manual juntamente com os POP.

O Alvará Sanitário ou licença sanitária é exigido com o prazo de 30 dias, a contar da data de assinatura do contrato, sob pena de rescisão, em apenas três contratos. A Constituição Federal da República Federativa do Brasil (1988) no seu artigo 200 atribuiu ao Sistema Único de Saúde (SUS) a competência de executar ações de vigilância sanitária e epidemiológica (inciso II) e de fiscalizar e inspecionar alimentos, compreendendo o controle de seu teor nutricional, bem como bebidas e águas para consumo humano (inciso VI). A Vigilância Sanitária é definida como: "um conjunto de ações capaz de eliminar, diminuir ou prevenir riscos à saúde e de intervir nos problemas sanitários decorrentes do meio ambiente, da produção e circulação de bens e da prestação de serviços de interesse da saúde" (Lei n. 8080, 1990). A atuação da Vigilância Sanitária é por meio de inspeções para averiguar a propriedade dos alimentos e as condições sanitárias das UAN hospitalares e intervir.

Uma ferramenta importante e obrigatória para o controle higiênico-sanitário é a análise de amostras das preparações. Todos os contratos trazem o item "controle bacteriológico" com as instruções de como realizar esse procedimento (tipo de recipiente; identificação; frequência de coleta e análise; tempo para guardá-las). Estudo realizado por Souza et al. (2021) no estado do Piauí verificou que os principais alimentos responsáveis por surtos alimentares nos anos entre 2015 e 2019 na região foram as preparações mistas e a água.

Nos TR há um subtópico que traz dados sobre como deve ser feita a higiene pessoal; o uniforme padrão e equipamentos de proteção individual (EPI) - troca, aparência, composição -; e o controle de saúde. Todo o cuidado com os trabalhadores de UAN se dá pela importância desses profissionais na produção de preparações higiênicas e de seu conhecimento para prevenção de grande parte das Doenças Veiculadas por Alimentos (DVA) (Portaria CVS n. 5, 2013). Os treinamentos periódicos abordando temas da rotina dos profissionais são uma forma de garantir a qualidade do alimento. Seta et al. (2010) foram informados em quais unidades de alimentação hospitalares que as ações educativas existiam, porém, nenhuma delas apresentou programa e/ou cronograma de realizações, indicando falta de periodicidade.

Estudo realizado por Bou-Mitri, Mahmoud, Gerges e Jaoude (2018) em hospitais libaneses verificou que dos 254 
manipuladores de alimentos, a maioria respondeu de forma positiva as seguintes proposições: "lavar as mãos antes de manipular alimentos com apenas água reduz o risco de contaminação" (61,8\%); "usar as luvas ao manipular alimentos reduz o risco de transmissão de infecção aos consumidores" $(66,1 \%)$ e "usar as luvas durante o manuseio dos alimentos reduz o risco de transmissão de infecção para a equipe de serviços de alimentação" (74,0\%). Essas questões poderiam ser esclarecidas a partir de treinamentos periódicos.

O não cumprimento dos itens abordados neste estudo pode gerar multa para o contratado, informação presente no TR.

Dentre as limitações deste estudo, pode-se apontar a escassez de pesquisas anteriores sobre o tema abordado e o número de contratos analisados.

\section{Conclusão}

O Termo de Referência deve abranger o maior número de informações para evitar situações que comprometam a qualidade do alimento servido ao comensal, neste caso, ainda mais relevante por se tratarem de UAN hospitalares. Neste estudo, os Termos de Referências foram boas fontes de informações quanto às exigências da Vigilância Sanitária, provavelmente pelo poder que este órgão tem em penalizar, seja por notificação ou até interdição dos estabelecimentos. Já sobre a parte técnica, muitos dados importantes não estavam presentes. Foi observada a falta de informações em todas as Tabelas confeccionadas, referentes a itens importantes, como: a frequência das preparações, o controle de sobras, a higienização do reservatório de água, a avaliação da satisfação dos usuários e o Monitoramento da Atenção dietética prestada. São dados que impactam diretamente nas atividades conduzidas nas UAN. O que nos leva a considerar a necessidade de um TR mais específico para a área de nutrição.

São necessários outros estudos que analisem os Termos de Referência e sua aplicação no dia a dia das UAN para entender melhor quais os desafios em colocá-los em prática.

\section{Agradecimentos}

Ao Programa de Pós-graduação em Alimentos, Nutrição e Saúde da Escola de Nutrição da Universidade Federal da Bahia.

\section{Referências}

Associação Brasileira das Empresas de Refeições Coletivas [ABERC]. (2021) Mercado Real. https://www.aberc.com.br/mercadoreal.asp?IDMenu=21.

Abreu, E. S. D, Spinelli, M. G. N. \& Pinto, A. M. D. S. (2011). Gestão de unidades de alimentação e nutrição: um modo de fazer. Metha.

Agência Nacional de Vigilância Sanitária [ANVISA]. (1993). Portaria n. 1428, de 26 de novembro de 1993. Aprova, na forma dos textos anexos, o "Regulamento Técnico para Inspeção Sanitária de Alimentos", as "Diretrizes para o Estabelecimento de Boas Práticas de Produção e de Prestação de Serviços na Ârea de Alimentos" e o "Regulamento Técnico para o Estabelecimento de Padrão de Identidade e Qualidade (PIQ's) para Serviços e Produtos na Área de Alimentos". Determina que os estabelecimentos relacionados à área de alimentos adotem, sob responsabilidade técnica, as suas próprias Boas Práticas de Produção e/ou Prestação de Serviços, seus Programas de Qualidade, e atendam aos PIQ's para Produtos e Serviços na Área de Alimentos. https://bvsms.saude.gov.br/bvs/saudelegis/gm/1993/prt1428_26_11_1993.html.

Agência Nacional de Vigilância Sanitária [ANVISA]. (2004). Resolução RDC n. 216, de 15 de setembro de 2004. Dispõe sobre o regulamento técnico de boas práticas para serviços de alimentação. Diário Oficial da União. https://bvsms.saude.gov.br/bvs/saudelegis/anvisa/2004/res0216_15_09_2004.html.

Akutsu, R. C., Botelho, R. A. B., Camargo, E. B., Sávio, K. E. O. \& Araújo, W. C. (2005). Adequação das boas práticas de fabricação em serviços de alimentação. Revista de Nutrição, 18(3). https://www.scielo.br/j/rn/a/rS99Rx5FdZKGhbLBkX5FdvK/abstract/?lang=pt. 10.1590/S1415-52732005000300013.

Araújo. T. G., Botelho R. B. A., Akutsu, R. C. C. A. \& Araújo, W. M. C (2016). Conformity of food service units with legislation. Journal of Culinary Science \& Technology, 14(1), 75-89. https://www.tandfonline.com/doi/abs/10.1080/15428052.2015.1080643. 10.1080/15428052.2015.1080643.

Bardin, L. 2016. Análise de conteúdo. Edições 70. 
Bou-Mitri, C., Mahmoud, D., Gerges, N. E., Jaoude, M. A. (2018). Food safety knowledge, attitudes and practices of food handlers in Lebanese hospitals: A cross-sectional study. Revista Food Control, 94, 78-84. https://www.sciencedirect.com/science/article/abs/pii/S0956713518303220. 10.1016/j.foodcont.2018.06.032.

Cavaler, S., Heilman M., Santos, A. P., Ferreira, H. \& Fatel, E. (2018). Informações para planejamento e elaboração de cardápios, contidas em editais de licitação de restaurantes universitários em universidades federais do Sul do Brasil. Revista Demetra, 13(3),713-729. https://www.epublicacoes.uerj.br/index.php/demetra/article/view/32140.

Colares, L. G. T., Figueiredo, V. O., Martins, M. C., Andrade, L. P. (2014). Contratação de serviços terceirizados de alimentação e nutrição: orientações técnicas. Rubio.

Conselho Federal de Nutricionistas [CFN]. (2005). Resolução CFN n. 380/2005 - dispõe sobre a definição das áreas de atuação do nutricionista e suas atribuições, estabelece parâmetros numéricos de referência por área de atuação e dá outras providências. Diário Oficial da União.

Conselho Federal de Nutricionistas [CFN]. (2018). Dispõe sobre a definição das áreas de atuação do nutricionista e suas atribuições, indica parâmetros numéricos mínimos de referência, por área de atuação, para a efetividade dos serviços prestados à sociedade e dá outras providências. Brasília: Diário Oficial da União. https://www.cfn.org.br/wp-content/uploads/resolucoes/Res_600_2018.htm.

Constituição da República Federativa do Brasil de 1988. (1998). http://www.planalto.gov.br/ccivil_03/constituicao/constituicao.htm.

Decreto n. 10.024, de 20 de setembro de 2019. (2019). Regulamenta a licitação, na modalidade pregão, na forma eletrônica, para a aquisição de bens e a contratação de serviços comuns, incluídos os serviços comuns de engenharia, e dispõe sobre o uso da dispensa eletrônica, no âmbito da administração pública federal. http://www.planalto.gov.br/ccivil_03/_Ato2019-2022/2019/Decreto/D10024.htm.

Decreto-lei n. 200, de 25 de fevereiro de 1967. (1967). Dispõe sobre a organização da Administração Federal, estabelece diretrizes para a Reforma Administrativa e dá outras providências. http://www.planalto.gov.br/ccivil_03/decreto-lei/del0200.htm.

Lei n. 10.520, de 17 de julho de 2002. (2002). Institui, no âmbito da União, Estados, Distrito Federal e Municípios, nos termos do art. 37, inciso XXI, da Constituição Federal, modalidade de licitação denominada pregão, para aquisição de bens e serviços comuns, e dá outras providências. http://www.planalto.gov.br/ccivil_03/leis/2002/110520.htm.

Lei n. 11.346, de 15 de setembro de 2006. (2006). Cria o Sistema Nacional de Segurança Alimentar e Nutricional-SISAN com vistas em assegurar o direito humano à alimentação adequada e dá outras providências. http://www.planalto.gov.br/ccivil_03/_ato2004-2006/2006/lei/111346.htm.

Lei n. 8.080, de 19 de setembro de 1990. (1990). Dispõe sobre as condições para a promoção, proteção e recuperação da saúde, a organização e o funcionamento dos serviços correspondentes e dá outras providências. http://www.planalto.gov.br/ccivil_03/leis/18080.htm.

Lei n. 8.666, de 21 de junho de 1993. (1993). Regulamenta o art. 37, inciso XXI, da Constituição Federal, institui normas para licitações e contratos da Administração Pública e dá outras providências. http://www.planalto.gov.br/ccivil_03/leis/18666cons.htm.

Lei n. 8234/1991. (1991). Regulamenta a profissão de Nutricionista e determina outras providências. 1991. http://www.planalto.gov.br/ccivil_03/leis/1989_1994/L8234.htm.

Mello, J. F., Schneider, S., Lima, M. S., Frazzon, J. \& Costa, M. (2013). Avaliação de higiene e das boas práticas em UAN. Revista Alim. Nutr.Braz. J. Food $\begin{array}{lll}\text { Nutr., } & \text { 24(2), } & 175-182 .\end{array}$ bib.fcfar.unesp.br/seer/index.php/alimentos/article/viewFile/175/2146\#: :text=A\%20avalia\%C3\%A7\%C3\%A3o\%20da\%20higiene\%20das,frente\%20\%C3\% A0\%20lista\%20de\%20verifica\%C3\%A7\%C3\%A3o

Portaria CVS 6, de 10 de março de 1999. (1999). Regulamento técnico sobre os parâmetros e critérios para o controle higiênico-sanitário em estabelecimentos de alimentos. http://www.cvs.saude.sp.gov.br/zip/E_PT-CVS-06_100399.pdf.

Ramos, S. A., Souza, F. F. R., Fernandes, G. C. B., Carla G, Xavier, S. K. P. (2013). Avaliação qualitativa do cardápio e pesquisa de satisfação em uma unidade de alimentação e nutrição. Revista Alimentos e Nutrição, 24(1). http://serv-bib.fcfar.unesp.br/seer/index.php/alimentos/article/view/29/2319.

Seta, M. H., O'Dwyer, G., Henriques, P., Sales, G. L. P. (2010). Cuidado nutricional em hospitais públicos de quatro estados brasileiros: contribuições da avaliação em saúde à vigilância sanitária de serviços. Revista Ciência \& Saúde Coletiva, 15 (suppl 3), 3413-3422. https://www.scielo.br/j/csc/a/wjf3VJBCV3D4hnbxsR9d4qw/abstract/?lang=pt. 10.1590/S1413-81232010000900016.

Silva Júnior, E. A. (2013). Manual de controle higiênico-sanitário em serviços de alimentação. (6a ed.), Varela.

Souza, A. A., Lara, C. O., Lima, L. C. M. \& Xavier, A. G. (2011). Uma análise da terceirização em hospitais localizados na região metropolitana de Belo Horizonte. Revista Sociedade, Contabilidade e Gestão, 6(1). http://www.atena.org.br/revista/ojs-2.2.3-06/index.php/ufrj/article/viewFile/955/1099.

Souza, F. C. A. et al. (2021). Análise epidemiológica dos surtos de Doenças Transmitidas por Alimentos (DTAs) no estado do Piauí entre os anos de 2015 a 2019. https://rsdjournal.org/index.php/rsd/article/view/16756/15079. 10.33448/rsd-v10i7.16756.

Teixeira, S. M. F., Oliveira, Z. M. C. D., Rego, J. C. D. \& Biscontini, T. M. B. (1990). Administração aplicada às unidades de alimentação e nutrição. Atheneu.

Vieira, A. P. (2013). Gestão de contratos de terceirização na Administração Pública: teoria e prática. Fórum. 